\title{
Professional Practice Model Reforming of Information Security Specialty in Public Security College
}

\author{
Leng Jing \\ Department of Information Technology \\ Hubei University of Police \\ Wuhan, China \\ e-mail: daleng0127@ sina.com
}

\author{
Zhu Bo* \\ Orthopedics department, Tongji Hospital \\ Huazhong University of Science and Technology \\ Wuhan, China \\ e-mail: Jubal_cn@hotmail.com \\ (* Corresponding author)
}

\begin{abstract}
For the emerging domestic Information Security Specialty (ISS), we can draw of little successful experience directly on professional practice in this field, not to mention referring directly. In order to improve the professional practice quality of ISS students, measures are carried out as follows. First, the importance of information security professional practice in Public Security College was analyzed comprehensively. Second, based on the analysis results of situation and reasons causing shortcomings of information security professional practice of Hubei University of Police, improved methods and assessment methods of professional practice model have been proposed. These can overcome shortcomings of the original professional practice model, and improve effect of professional practice, so as to enhance the quality of information security personnel training.As an example happened in Hubei University of Police, in this paper current deficiencies of ISS students practice are analyzed and improved practice models are recommended spread out to gain better effect.
\end{abstract}

Keywords-Public Security Colleges; Information Security Specialty; Professional practice; Reform

\section{INTRODUCTION}

At present, information security technology in China is not well developed, and only a few universities set up Information Security Specialty (ISS), leading serious lack of talents of information security technology. After undergraduate information security specialty was first set up in Xidian University and Wuhan University in 2001, Hubei University of Police became one of the first batch of Public Security Colleges having information security specialty by setting her own ISS in 2002.

For the emerging domestic information security specialty, we can draw of little successful experience directly on professional practice in this field, not to mention copy directly

In order to improve effect of professional practice, taking Hubei University of Police ISS for example, improvement models and evaluation methods of practice are proposed, basing on the analysis of the present situation of professional practice and the shortcomings.

\section{IMPORTANCE OF PROFESSIONAL PRACTICE IN INFORMATION SECURITY TEACHING}

IIS aims to train senior engineering and technical personnel who master basic theory and method of information security systematically, and have professional knowledge and comprehensive ability of system engineering, computer and network technology.

As the Subject of regularization Police Education, public security colleges carry out information security education timely, to train with comprehensive information security expertise of high-tech talent for public security group. It aims to prevent and combat internal computer network crime, and participate in electronic information war against the foreign countries. A clear targeting is training Information Security application of police personnel, who have basic proficiency of system security maintenance, analysis, design, using of computer technology and information security theory knowledge; have engaged in network security event handling and network security defense ability to work; are familiar with information security, public security, judicial, administrative systems, as well as information security of important information systems; and have a strong awareness of information security, and basic service quality of preventing, analyzing, surveying the network security events

It requires that teaching must be based on theoretical knowledge, combined with practical hands-on, to strengthen students' practical ability of professional skills and ability to operate divergent practices.

Professional practice teaching is an important channel linking theory with practice, and an important way to train professional practice ability of students, also is a teaching unit in practice teaching system of university, which has the longest teaching time, the most stringent professional and systematic, the most comprehensive content internships, the most important tasks of teaching.

Hubei University of Police is a liberal arts-based public security college, while Information security specialty has distinctive characteristics and employment direction as the minority of technical specialties in our college. The teaching and practice segments of IIS are very different from the corresponding segments of general liberal arts education. Especially, professional practice can not be equated to vocational education. It should 
strengthen the integration of professional knowledge and skills of students, and make their ability related to all aspects of specialty to exercise during professional application.

\section{THE STATUS OF INFORMATION SECURITY PROFESSIONAL PRACTICE IN OUR COLLEGE}

By 2014, there are only 77 colleges, which have information security specialty. The Time to form a specialty system is only about a decade. Many colleges are still in the exploratory phase of specialty construction. The development of information security specialty is still not perfect, and the model of professional practice is not mature enough. Constrained by the mission statement of each college, software and hardware facilities, professional practice did not play well in the role of personnel training, which did not achieve the desired effect.

\section{A. Monotonous mode, lack of specialty features}

In our college, the majority of specialties are liberal arts, while engineering specialties are rarely. As one of the few engineering specialties, information security specialties are less associated with other specialties. So the features of Information Security specialty can easily be buried, and the importance of professional practice can easily be overlooked, and practice process and method are easy to be liberal arts.

At present, the students' professional practice is coordinate arranged by Dean's Office. Students will be assigned to public security departments at all levels, whose police staff are insufficient within the scope of the province. In this mode, determination of student's practice units and departments is not according to the specialty, but in view of the practical demand of public security department. So, most of the information security specialty students went into the same the grass-roots units of public security, with the other students of liberal arts specialty, such as investigation and public security.

\section{B. Professional practice is equivalent to career internship}

The places of information security specialty students in our college are combat units of public security department at all levels in the province. Within about six months of practice, students mainly involved in the daily work of grassroots police officers, such as 110 alarming, patrol, trial, receive messes, etc. These administrative matters can help students more comprehensive, in-depth understanding of the general workflow of public security departments. It will undoubtedly be able to help students build on proper perspective and understanding of the police work, and significance to vocational education.

However, professional practice and career internship is largely not completely identical. Professional practice aims to enable students to learn basic knowledge and skills in practice, verification and innovation. For information security specialty, students can participate in the project to strengthen basic skills in software development; can use what they have learned to participate in the network security supervision and protection tasks, applying specialized theory to practice, and improve hands-on ability; can participate in the application system maintenance and operational control of background data, exercising software control and database management capabilities $\cdots$ The career internship is designed to help students understand the conditions and business processes of industry or employment, in order to facilitate the future entry into the industry successfully.

The professional practice is equivalent to career internship for investigation and public security specialties in police academies. But as mentioned above, for this nonpublic security direction of information security specialty, professional practice has a completely different targeting and content with career internship, which can't replace each other.

From currently implementation of arrangements to our college information security professional practice, the professional practice is largely confused as a career internship. Professional practice is in fact a mere formality, just be satisfied with the completion of specialty scheduled tasks, which can't really play the role of professional practice.

\section{C. practice programs are executed incompletely}

Take our college grade 2011 information security specialty training program for example, Practice stage is about 20 weeks, arranged in the sixth semester of the third year of teaching cycle, as shown in table 1. Prior to this, the students have completed all of the public basic course and most of the basic specialized courses and specialized courses. They have had a more comprehensive understanding of specialty direction, and also had a certain degree of accumulation on the knowledge and skills related to the specialty. These early groundwork of knowledge is the foundation for the professional practice successfully launched, but also provides the necessary knowledge guarantees.

Students can achieve internalization and enhance the skills of knowledge in the practice process, and verify the theory in practice, in order to achieve the intended purpose of the teaching program.

As the public security college is different from the ordinary university, original teaching programs tend to be disrupted for some reason, in the actual teaching process. As security forces of the national, provincial or municipal major events need to be strengthened, our college will often be required to deploy a significant number of students to participate in the implementation of security tasks to assist the police and government authorities to maintain order, in order to compensate for the lack of local police force. So naturally curriculum teaching schedule will be affected, these are objective problems.

In addition, since the college has not enough awareness of the role and importance of information security professional practice, distinction between specialty and disciplines often was overlooked. Such as the time of the 2011 Information Security professional practice is advanced to the fifth semester, in the actual implementation. It Make scheduled for the 5th semester of specialized courses to be delayed, while practice interrupt basic courses and specialized courses, which disrupted the chain of technical specialties. Students did practice when they have not yet build a complete structure of subject knowledge, which is difficult to achieve the desired target of practice. 


\section{PRACTICE MODEL IMPROVEMENTS}

For the restriction of various factors such as teaching conditions, practice environment, sound practice results under unified model were hardly expected. basing on analysis results of characteristic of information security specialty and the needs for information security specialists, specific analysis and conclusion were done on current practice situation of information security college students, hoping for get rid of the unified assigned practice mode by a new one characteristic as students practicing initiatively and in various forms with teachers' piloting, having sufficient choice, autonomy and more flexible culture

TABle I. Professional PRActice Teaching Schedule

on practical ability, and better results. Improved practice model is shown in Fig .1.

\begin{tabular}{|c|c|c|c|c|c|c|c|c|c|}
\hline \multirow{2}{*}{ TABLE II. Project } & \multicolumn{8}{|c|}{ Weeks assigned each semester } & \multirow{2}{*}{ Total } \\
\hline & 1 & 2 & 3 & 4 & 5 & 6 & 7 & 8 & \\
\hline $\begin{array}{l}\text { entrance education and } \\
\text { military training }\end{array}$ & 4 & & & & & & & & 4 \\
\hline $\begin{array}{c}\text { Course Desig (be in } \\
\text { winter/summer vacation) }\end{array}$ & & & 2 & & 2 & 3 & 2 & & 9 \\
\hline $\begin{array}{c}\text { Comprehensive simulation } \\
\text { practice }\end{array}$ & & & & & & & & 2 & 2 \\
\hline Professional practice & & & & & & 20 & & & 20 \\
\hline $\begin{array}{c}\text { Graduation Practice and } \\
\text { Design }\end{array}$ & & & & & & & & 8 & 8 \\
\hline Total & 4 & & 2 & & 2 & 23 & 2 & 10 & 43 \\
\hline
\end{tabular}

A. College-Enterprise cooperation model

Field practice is the main means of practice and the traditional methods of undergraduate students accumulating professional practice experience. To meet the need of professional direction, college contact with computer or information security companies, enterprises, institutions, even public security departments as practicing base, which have the ability of hosting students and meeting the demand of practice, especially have professional counterparts. When practicing in relevant project, students could understand the process and management system of the project, make familiar with system development process and developing techniques, then apply the knowledge on system installation, maintenance, management, security and stability when running system.

Of course, due to the different levels and abilities of students, they can join the project in different breakthrough point (can break through the project in different point), such as probation, participation, solo job. The ability of communicating with leaders, employees, customers, the frontier knowledge of information security techniques and

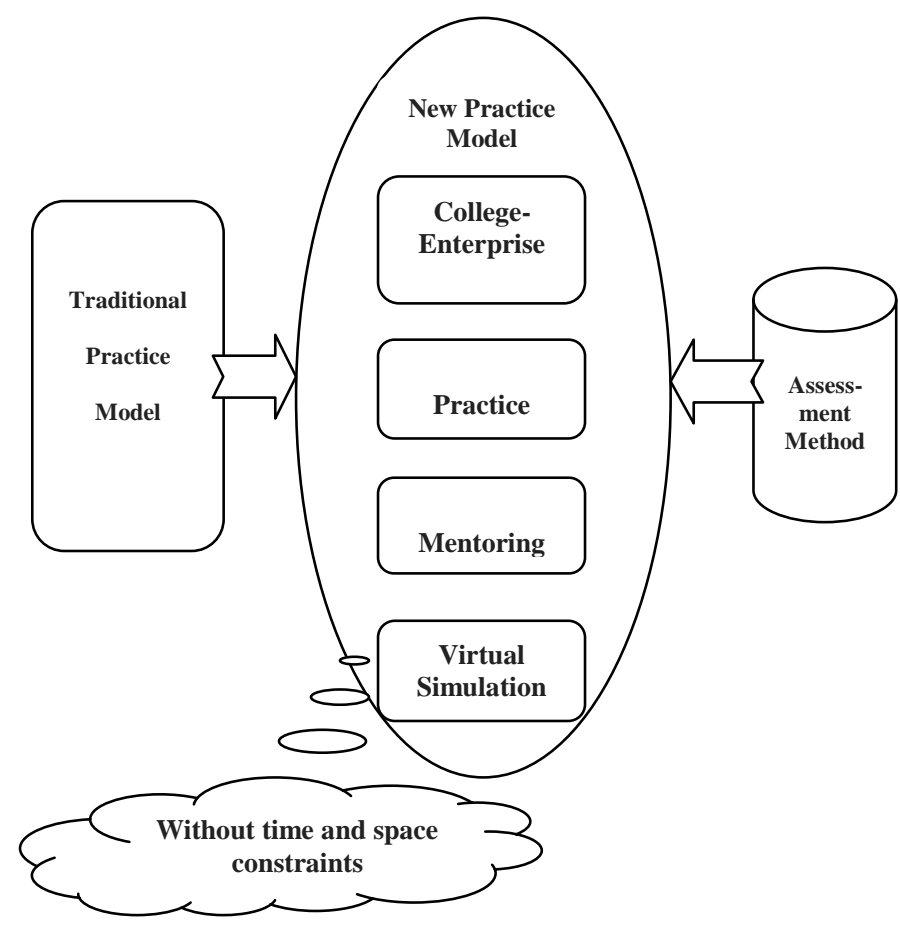

Figure 1. Improved practice model

cutting-edge technology applying, enable students understanding the demand for security professionals and for the needs of applying knowledge and technology in the future.

The stable and long-last cooperation relationship between college and practice units could contribute to the continuity and stability of applying practicing. However, the specific arrangement need to fit for the change of work environment and adjusted requirements.

\section{B. Practice base model}

Practice base model is one of the popular practice model adopted by applied specialties recently, and the same by ISS. Schools can build IS training base on campus or off-campus, develop and apply a training plan based on the specific needs of professional and student, with overall responsibility of students' learning, work and life.

Training base organize practice as a virtual companyaccording the 'employment-oriented' the principle and the 'job skills standard' training system, develop students' integrated professional quality, team-work and individual skills by the way of project developing and IS managing. In the virtual company, students are not only the project members to plan, organize, cooperate and complete the mission, but also the technician members to resolve problems according job skill standard, then competent to job finally.

The training base offer students not only professional skill training, including advanced courses and integral standard project developing experience, but also employment opportunities provided through training base information platform. Thus, the costs on base construction and maintenance are relatively high.

\section{Mentoring model}

The two models mentioned above are group practicing, accomplished practice in practice unit or training base within 1 to 3 months. Mentoring model is more flexible. 
Students will be divided into beginner, intermediate and advanced groups in accordance with students' interest, knowledge basis, learning ability and goals, and then trilled for basic knowledge, skills and technology improvement, application innovation respectively. Different level tasks and goals will set to different groups, to be finished in group by the mentor of teacher.

\section{Virtual simulation model}

When short of practicing places, Virtual Simulation Lab could be the choice. Virtual Simulation Lab could mimic the information platform, environment, so that students could accomplish tasks under different scenarios by themselves.

In virtual environment, students can understand all kinds of application demands in quiet short time, such as network prevention and virus killing, intrusion detection systems, VPN (Virtual Private Network) Construction, firewall, data backup and restore. With more practicing opportunity offered, students' initiative was inspired by choosing different simulation project according their own situations. Practicing timing is also more flexible in this virtual environment.

In addition to the models listed above, there are many other fine models. Using the methods separately or hybrid is depending on the teaching process. All in all, professional practice should be carried out in various ways instead of the traditional way, so that students could be widened their horizon and cultured positively and initiatively under tutors' guidance. Practicing places are expanded by network technology, video technology and so on; practicing time is unchained by compound practice models. Flexible teaching models and lively learning methods lead to active mind and a better practice effect.

\section{PRACTICE ASSESSMENT}

Various practice models correspond with different assessment methods. In the field practice model, tutors draw a comprehensive conclusion on students by practice unit report, paper test, practice log or reports, students' attitude and overall performance evaluation. In training base model, students could be evaluated on site. In mentor model, tutors assess on students' performance according to result of project. In virtual simulation model, assessment could be done by software automatically according knowledge and skill level.
This kind of practice can be carried out in campus, also in students' spare time. Students learn, practice and communicate with tutors occasionally, reporting project progress; the tutors guide the students practicing activity on individual character.

\section{CONCLUSION}

Professional practice plays an important role in practicing and innovation culture of ISS students. As an example happened in Hubei Police University, in this paper current deficiencies of ISS students practice are analyzed and improved practice models are recommended spread out to gain better effect.

\section{REFERENCES}

[1] Zhang Tianchang,Xu Wei, "A study on the construction of unique features of the Information security subject in Public security colleges and universities,"Journal of Hubei Police officer College, 2005.9

[2] Han Xincai,Wang Cunwen,etc."The Innovation Ideas and Measures of Colleges to Improve the Teaching Quality of Professional practicee," The Science Education Article Collects, 2011.9

[3] Wu Dingxue,Chen Xiaolin., "The model of Computers professional practice the undergraduate employment market-oriented," Computer Education, 2011.3

[4] Ma Shuangchen,etc. " Reform thinking and practical procedure of university professional practicee," Experimental Technology and Management, 2013.1

[5] Wang Youming,Wang Liqun, "The Research on Computer specialized graduation practice," Computer education,2007.11

[6] Liu Yangyang, "Reflections on optimizing the teaching system of information security specialty in public security colleges," Education and Vocation,2011.3

[7] Hao Bin , "Problems in Practice Teaching and Solutions,"Journal of Tangshan College, 2010.5

[8] Ou Shengbin,Chen Jun, "Exploration and Practice Professional Internships in Application-Oriented Universities," Research and Exploration in laboratory,2011.10

[9] Liu Yanhui,"Curriculum teaching practice for computer specialty," Journal of Luohe Vocatioanla Technology college,2013.3

[10] Chen Zhenwu, Zhang Jiyan, Liang Junping, “ Exploration of construction of computer professional practice base of local university," Journal of LongYan University,2012.4 